\title{
Stage 0 mucinous adenocarcinoma in situ of the urachus
}

\author{
A B Paul, C R Hunt, J M Harney, J P R Jenkins, R F T McMahon
}

\begin{abstract}
Adenocarcinomas of the urinary bladder are rare $(1-5 \%$ of bladder tumours) and of notoriously poor prognosis. About one third of such tumours arise in urachal remnants related to the bladder. This is believed to be the first report of in situ change in the urachal remnant. The patient presented with mucusuria and computed tomography showed a typical urachal cyst. After excision the cyst was found to contain mucinous adenomatous epithelium but without invasion of the basal lamina. Pathological stage is the best prognostic indicator in urachal tumours. Prompt investigation and management of mucusuria may allow the diagnosis of urachal tumours in this preinvasive stage.

(f Clin Pathol 1998;51:483-484)
\end{abstract}

Keywords: urachus; adenocarcinoma; carcinoma in situ

Adenocarcinoma of the urachal remnant accounts for $0.17-0.34 \%$ of all bladder malignancies and $20-39 \%$ of primary adenocarcinomas of the bladder. ${ }^{1}$ Adenomas of the urachus are even rarer. ${ }^{2}$ We describe a case of urachal mucinous adenocarcinoma in situ presenting at a preinvasive stage.

Case report

A 68 year old man presented with haematuria and mucusuria. He had no other abdominal symptoms. Abdominal and digital rectal examinations were unrevealing and sigmoidoscopy and barium enema showed a normal large bowel without evidence of colovesical fistula. At cystoscopy, a $1.5 \mathrm{~cm}$ diameter raised lesion of the dome of the bladder was seen. Mucus was discharging into the bladder lumen from a central punctum. Histopathological examination of biopsies from the lesion showed mucus secreting glandular epithelium, consistent with a patent urachus. The epithelium showed mild atypia. Subsequent computed tomography showed a $3 \mathrm{~cm}$ lesion anterior to the bladder dome. The lesion was indenting the bladder dome and contained low attenuation material thought to represent mucus (fig 1).

A partial cystectomy of the dome of the bladder, taking the median and medial umbilical ligaments and the umbilicus en bloc, was performed. Histopathology revealed a mucus filled cavity of $3 \mathrm{~cm}$ diameter, communicating with the bladder lumen through the punctum noted at cystoscopy. The lining of the cavity bore an exophytic papillary area $1.8 \mathrm{~cm}$ in

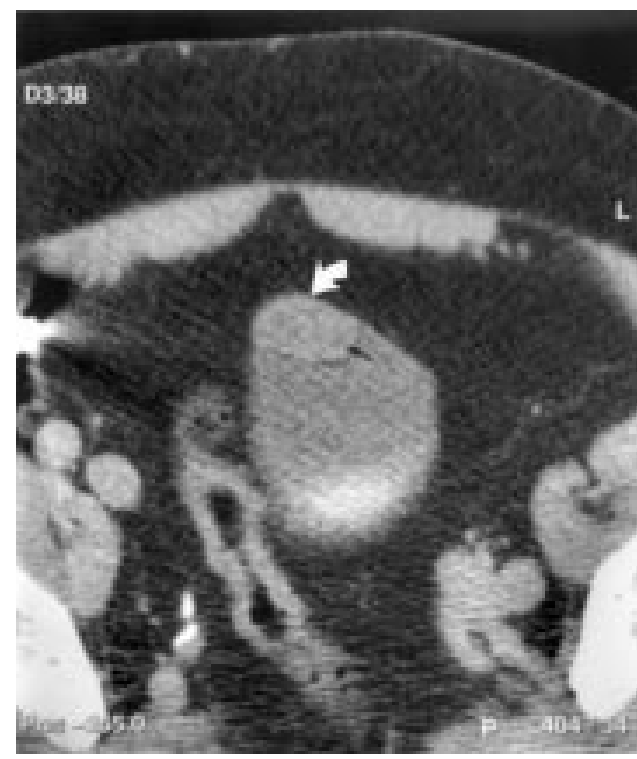

Figure 1 Contrast enhanced computed tomography showing a $3 \mathrm{~cm}$ soft tissue mass (curved arrow) in the juxtavesical segment of the anterior bladder dome, with low attenuation material (measuring 12 Hounsfield units) consistent with mucus (straight arrow). No calcification was seen in the lesion.

diameter, which was found on microscopy to consist of fine fibrovascular cores with a complex architecture (fig 2). The lining of the cyst and the epithelium covering the papillary lesion consisted of mucus secreting cells showing nuclear pleomorphism and abundant mitoses. There was no evidence of invasion through the basal lamina (fig 3). The appearances amounted to those of a mucinous adenocarcinoma in situ. The remainder of the specimen was minutely examined for other areas of neoplastic change, but none were found and no other areas of epithelialised patent urachus were identified.

The patient made an uneventful recovery from surgery and is clinical and ultrasonographically free of recurrence after one year.

\section{Discussion}

Mucusuria occurs in around $25 \%$ of patients with urachal tumours. It is a rare urological symptom and always merits full investigation with cystoscopy and intravenous urogram, and commonly, as here, computed tomography. Computed tomography is the most sensitive imaging mode in the investigation of urachal tumours. ${ }^{3}$ As this case shows, the urgent investigation of the symptom of mucusuria may allow the diagnosis of tumour to be made when surgical cure is still possible.

Tumours arising within the urachus are divided into benign (adenoma) or malignant
Accepted for publication 10 December 1997 


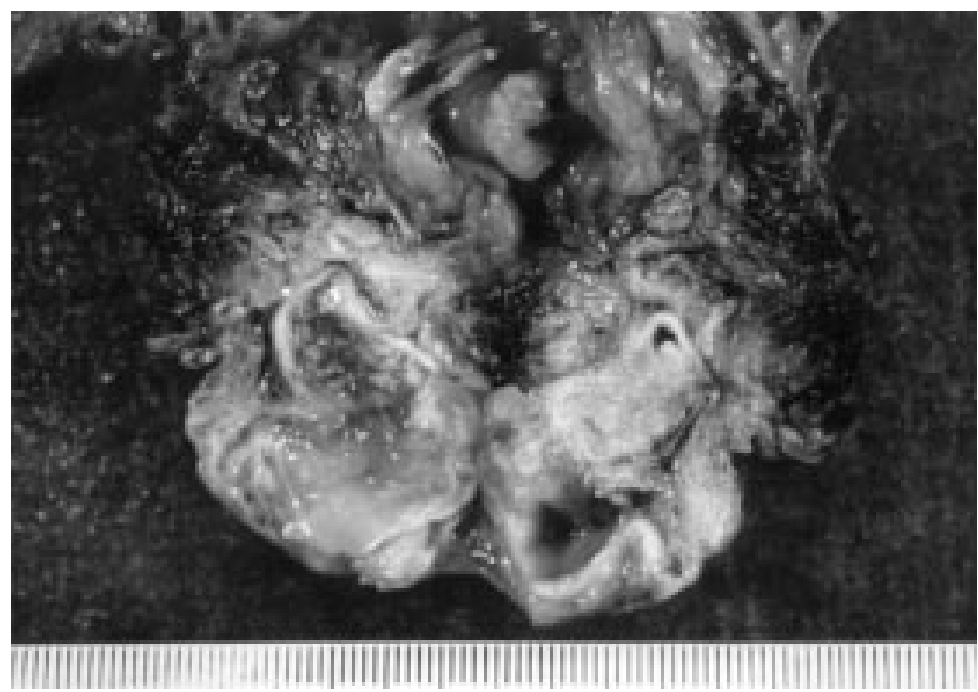

Figure 2 The cystic cavity excised from the dome of the bladder containing glairy fluid and, above, an exophytic papillary area of tumour.

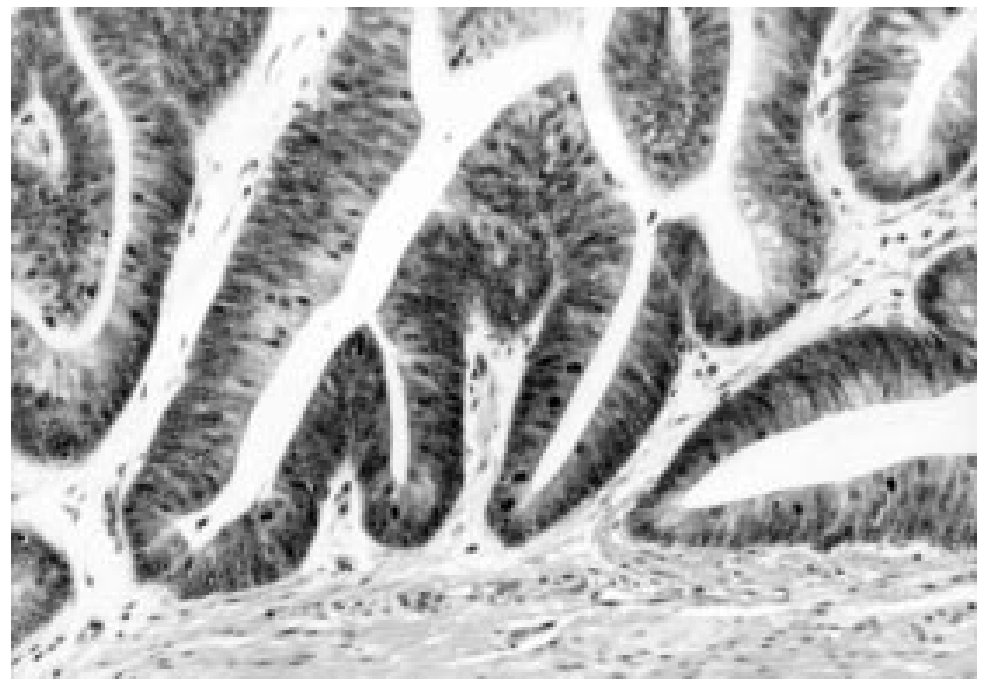

Figure 3 Histologically the urachal lesion is lined by a papillary tumour showing focal mucus production, nuclear pleomorphism, and abundant mitotic figures. The basement membrane is intact (haematoxylin and eosin, $\times 595$ ).

lesions (adenocarcinoma). Most adenomas of the urachus are multiloculated cystic tumours which are lined by mucus secreting epithelium resembling that of the colon or rectum. ${ }^{2}$ Mucin producing adenocarcinomas represent $69 \%$ of malignant urachal neoplasms. ${ }^{1}$ This patient presented with a non-invasive stage 0 lesion with histological features intermediate between these two categories.

Grignon et al have reported their experience of 24 urachal neoplasms among a series of 72 primary vesical adenocarcinomas. They found a survival rate of $61 \%$ at five years and $46 \%$ at 10 years. ${ }^{4}$ In 41 patients with urachal adenocarcinomas, Nakanishi et al have examined the prognostic significance of ploidy, Ki-67 staining, and nucleolar organising region counts. They found in multivariate analysis that only differentiation and stage were useful prognostic factors. ${ }^{5}$ A urachal adenocarcinoma arising in a pre-existing adenoma has previously been reported. ${ }^{6}$

As far as we are aware, this is the first report of a urachal tumour at the stage of carcinoma in situ. We raise the possibility that, as in colonic adenocarcinomas, ${ }^{7}$ there is a biological continuum of behaviour of glandular neoplasms in the urachus from benign to malignant. The lesion described here represents the premalignant phase of that continuum. The finding here of premalignant change in a urachal remnant stresses the importance of a wide excision of the urachus in its entirety, in the management of urachal tumours.

1 Sheldon CA, Clayman RV, Gonzalez R, et al. Malignant urachal lesions. F Urol 1984;131:1-8.

2 Eble JN, Hull MT, Randall GR, et al. Villous adenoma of the urachus with mucusuria: a light and electron microscopic study. F Urol 1986;136:1240-4

3 Hayes WS. The urinary bladder. In: Davidson AJ, Hartman DS, eds. Radiology of the kidney and urinary tract, 2nd ed. Philadelphia: WB S

4 Grignon RJ, Ro JY, Ayala AG, et al. Primary adenocarcinoma of the urinary bladder: a clinicopathologic analysis of 72 cases. Cancer 1991;67:2165-72.

5 Nakanishi K, Kawai T, Suzuki M, et al. Prognostic factors in urachal adenocarcinoma: a study in 41 specimens of DNA status, proliferating cell-nuclear antigen immunostaining, and argyrophilic nuclear-organizer region counts. Hum Pathol 1996;27:240-7.

$6 \mathrm{Ng} \mathrm{KJ}$, Newman P, Price-Thomas JM. Carcinoma of the urachus associated with urachal adenoma. Br F Urol 1991; 67:215-16.

7 Kinzler KW, Vogelstein B. Lessons from hereditary colorectal cancer. Cell 1996;87:159-70. 